\title{
ANALYSIS OF DIELECTRIC PROPERTIES OF LITHIUM PHOSPHATE GLASSES
}

Dielectric relaxation spectra of lithium phosphate glasses are used to analyze the change of real and imaginary part of complex permittivity including loss tangent of ion conductive glasses. The experimental results getting from a.c. and d.c. electric measurements on Li phosphate glasses are analyzed, discussed and compared. Frequency dependence of the permittivity spectra is found to be consistent with the analysis of d.c. electrical conductivity. The universal a.c. conductivity law (universal dynamic response) for glass ionic conductor was confirmed. Arrhenius graphs constructed from a.c. and d.c. electrical measurements including loss tangent are used to characterize the relaxation processes and transport mechanisms connected with the mobility of conductive ions.

Keywords: Li phosphate glasses, conductivity and dielectric relaxation spectroscopy, relaxation and transport processes.

\section{Introduction}

Solid electrolytes present numerous potential advantages compared to liquid electrolytes, including absence of liquid containment and leakage problems, ability to operate with more reactive electrodes over a wider temperature range, and the possibility of miniaturization using thin-film-processing techniques. They are an important part of electrochemical devices such as electrochronic displays and sensors, solid-state batteries, electrochemical pumps, capacitors, time switches, etc. [1, 2].

General requirements for practical solid electrolytes are high ionic conductivity, stability with respect to thermal and electrochemical decomposition, suitable mechanical properties, ease of fabrication, and reasonable cost.

Lithium-ion conductive glasses have been widely studied due to their potential application as solid-state amorphous electrolytes in secondary batteries [1]. It was found that amorphous character of this material and the presence of nitrogen increase conductivity compared to that of the crystalline compound. The increase in conductivity is supposed to be related to the formation of $\mathrm{P}-\mathrm{N}$ bonds which replace $\mathrm{P}-\mathrm{O}$ ones leading to a more reticulated anionic network [2].

The optical and electrochemical properties of lithium phosphorous oxynitride (LiPON) thin films have been studied and successfully applied in lithium microbatteries [3]. LiPON exhibits a single $\mathrm{Li}^{+}$-ion conducting phase with an average conductivity of $(2.3 \pm 0.7) \times 10^{-6} \mathrm{~S} / \mathrm{cm}$ at $25^{\circ} \mathrm{C}$ and an average activation energy of $\mathrm{Ea}=(0.55 \pm 0.02) \mathrm{eV}[3]$.
In this contribution we present results obtained by electric investigation of lithium phosphate glasses with different $\mathrm{Li} / \mathrm{P}$ ratios with compositions $\mathrm{xLi}_{2} \mathrm{O} \cdot(1-\mathrm{x}) \mathrm{P}_{2} \mathrm{O}_{5}(x=55,57.5 \mathrm{~mol} \%)$ and oxynitride phosphate glass prepared through the thermal treatment under ammonia atmosphere of the sample with initial composition $(x=55 \mathrm{~mol} \%)$.

\section{Theoretical principles}

Dielectric relaxation spectroscopy is a powerful technique for the study of ion transport processes in fast ion conductive glasses. In general, using this spectroscopy, we can study molecular and ionic dynamics of charge carriers and dipoles [4], we can observe different systems from gases to solid substance.

The central quantities in this context are the dielectric displacement $\boldsymbol{D}$ and the electric field $\boldsymbol{E}$, with the dielectric permittivity $\varepsilon_{r}$ using the SI system being defined by

$$
\boldsymbol{D}=\varepsilon_{r} \varepsilon_{0} \boldsymbol{E}=\varepsilon_{0} \boldsymbol{E}+\chi \varepsilon_{0} \boldsymbol{E}=\varepsilon_{0} \boldsymbol{E}+\boldsymbol{P},
$$

where $\varepsilon_{0}=8.854 \times 10^{-12} \mathrm{AsV}^{-1} \mathrm{~m}^{-1}$ is the permittivity of vacuum, $\chi=\varepsilon_{r}-1$ is the susceptibility and $\boldsymbol{P}$ is the polarization. It has been observed that the determining the imaginary part of the complex dielectric constant $\left(\varepsilon^{\prime \prime}\right)$ compared to the real part $\left(\varepsilon^{\prime}\right)$ play a crucial role in the study of fundamental properties of investigated materials [5], where $\varepsilon^{\prime}(\omega)$ and $\varepsilon^{\prime \prime}(\omega)$ characterize the refractive and absorptive properties of the material, respectively. Using the functions

\footnotetext{
* Peter Hockicko ${ }^{1}$, Peter Bury ${ }^{1}$, Francisco Munoz ${ }^{2}$

${ }^{1}$ Department of Physics, Faculty of Electrical Engineering, University of Zilina, Slovakia, E-mail: hockicko@fyzika.uniza.sk

${ }^{2}$ Instituto de Ceramica y Vidrio (CSIC), Madrid, Spain
} 


$$
\varepsilon^{*}(\omega)=\varepsilon^{\prime}(\omega)-j \varepsilon^{\prime \prime}(\omega)
$$

is common in practice for presenting dielectric relaxation data for materials in which the motion of charges is dominated, where the position $\omega_{0}=1 / \tau_{0}$ of a peak in the loss component $\varepsilon^{\prime \prime}(\omega)$ outlines a characteristic time scale of the orientational molecular mobility. For ionically conducting glasses no equivalent feature in $\varepsilon^{\prime \prime}(\omega)$ is found which immediately sets a time scale for ionic mobility [6]. In the ion-conducting materials the polarization and conduction are, therefore, integrated into a single, continuous process. The loss tangent defined by relation

$$
\tan \delta(\omega)=\varepsilon^{\prime \prime}(\omega) / \varepsilon^{\prime}(\omega)
$$

can be also used for the relaxation spectroscopy that reflects the basic features of the relaxation processes of mobile ions. This quantity is related to the attenuation constant (or absorption coefficient) of an electromagnetic wave propagating in a material. The activation energies of the relaxation processes can be estimated from the plots of $\log \mathrm{f}$ vs. $1 / T_{\max }$ were $T_{\max }$ can be found using the isochronal peaks of $\tan \delta(\omega, T)$. These plots are straight lines in accordance with Arrhenius equation

$$
f=f_{0} \exp \left(-E_{a}^{\operatorname{tg} \delta(\omega)} /\left(k_{B} T_{\max }\right)\right),
$$

where $f$ is the frequency of the applied electrical field, $f_{0}$ is the preexponential factor. $E_{a}^{\operatorname{tg} \delta}$ is the activation energy associated to the dielectric loss, $k_{B}$ is the Boltzmann constant.

The electrical conductivity $\sigma$ of many solids including glasses, polymers and crystals has been shown to consist of a frequency independent and a strongly frequency dependent component [7]. Experimental data in a limited frequency region revealed that the overall frequency dependence of $\sigma$ or the so called "universal dynamic response" (UDR) of ionic conductivity can be approximated by the following simple relation

$$
\begin{aligned}
& \sigma(\omega)=\sigma_{d c}+A \omega^{s} \\
& \sigma_{d c}=\sigma_{0} \exp \left(-E_{a}^{d c} /\left(k_{B} T\right)\right),
\end{aligned}
$$

where $\omega(=2 \pi f)$ is the angular frequency of measurement. For a typical ionic conductor containing moderate to high concentration of mobile ions, $s \approx 0.5$, and both $\sigma_{d c}$ and A follow Arrhenius type strong temperature dependencies. In Eq. $6 \sigma_{0}$ is the pre-exponential factor, $E_{a}^{d c}$ is the activation energy of the ion transport through hopping processes which can be determined from the dc measurements.

\section{Experimental details}

The lithium phosphate glasses with composition $\mathrm{xLi}_{2} \mathrm{O} \cdot(1-\mathrm{x})$ $\mathrm{P}_{2} \mathrm{O}_{5}(x=55,57.5 \mathrm{~mol} \%)$ were obtained by conventional meltquenching technique. Stoichiometric amounts of reagent grade raw materials $\mathrm{Li}_{2} \mathrm{CO}_{3}$ (Aldrich, 99\%) and $\left(\mathrm{NH}_{4}\right) 2 \mathrm{HPO}_{4}$ (Merck, 99\%) were weighed and mixed. The batches were calcined in porcelain crucibles held in an electric furnace at a temperature up to $450{ }^{\circ} \mathrm{C}$, and then melted in a gas furnace (propane/air) during $1 \mathrm{~h}$ at temperatures ranging from $800{ }^{\circ} \mathrm{C}$ to $1000{ }^{\circ} \mathrm{C}$ depending on composition. The compositions of the glasses are given by their molecular formula as $\mathrm{Li}_{1.22} \mathrm{PO}_{3.11}$ and $\mathrm{Li}_{1.35} \mathrm{PO}_{3.18}$ for $\mathrm{Li}_{2} \mathrm{O}$ contents of 55 and $57.5 \mathrm{~mol} \%$, respectively [2].

The oxynitride lithium phosphate glasses were obtained through ammonolysis of base glasses in an $\mathrm{Al}_{2} \mathrm{O}_{3}$ gas-tight tube furnace at temperatures ranging from $600{ }^{\circ} \mathrm{C}$ to $750{ }^{\circ} \mathrm{C}$ and treatment times of $3 \mathrm{~h}$. Base glasses were placed in graphite moulds acting as individual "crucibles" of $2 \mathrm{~cm}$ in diameter and $5 \mathrm{~mm}$ deep. The furnace was heated up to the treatment temperature at a constant heating rate of $10 \mathrm{~K} \mathrm{~min}^{-1}$ under $\mathrm{N}_{2}$ flow. In the present work three glass compositions of prepared set of samples [2] are studied by dielectric relaxation and conductivity spectroscopy: $\mathrm{Li}_{1.22} \mathrm{PO}_{3.11}$ (B), $\mathrm{Li}_{1.35} \mathrm{PO}_{3.18}(\mathrm{C})$ and $\mathrm{Li}_{1.22} \mathrm{PO}_{2.80} \mathrm{~N}_{0.21}(\mathrm{BN})$.

The real and imaginary parts of the complex dielectric permittivities $\left(\varepsilon^{\prime}, \varepsilon^{\prime \prime}\right)$ and loss tangent $(\tan \delta)$ were calculated from the values obtained from the measurements in frequency ranges $50 \mathrm{~Hz}$ - 1 MHz by FLUKE PM 6306 impedance analyzer.

The sample $\mathrm{C}$ was chosen as representative of investigated glass system to present the experimental investigation by dielectric relaxation spectroscopy. The temperature dependence of both real and imaginary part of relative dielectric function $\varepsilon_{r}{ }^{*}(\omega, T)=\varepsilon_{r}{ }^{\prime}(\omega, T)-$ $-j \varepsilon_{r}^{\prime \prime}(\omega, T)$, for all sample were investigated.

\section{Results}

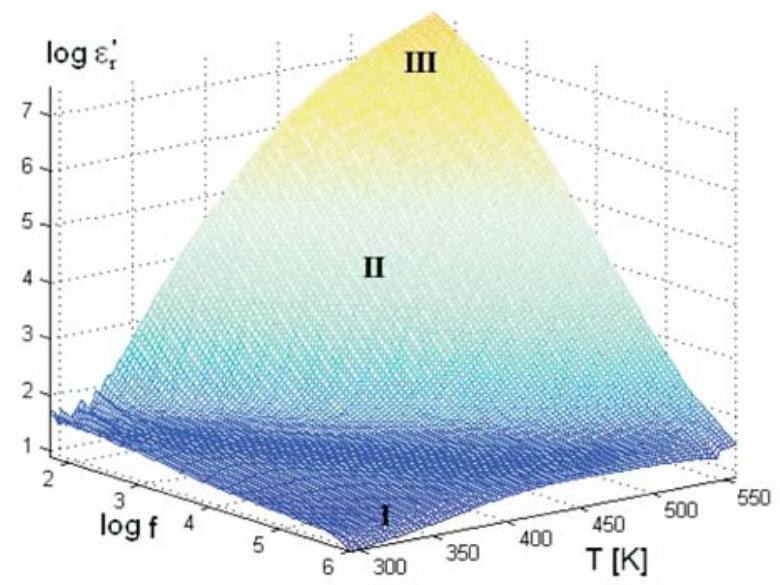

Fig. 1 Temperature and frequency dependence of real part of relative permittivity in $3 D$ form

Three-dimensional (3D) plots of measured both real $\left(\varepsilon_{r}{ }^{\prime}\right)$ and imaginary part $\left(\varepsilon_{r}^{\prime \prime}\right)$ of complex relative permittivity $\varepsilon_{r}^{*}$ as a function of temperature and frequency are shown in 3D presentation (in Figs. 1 and 2), respectively. From these pictures can be iden- 


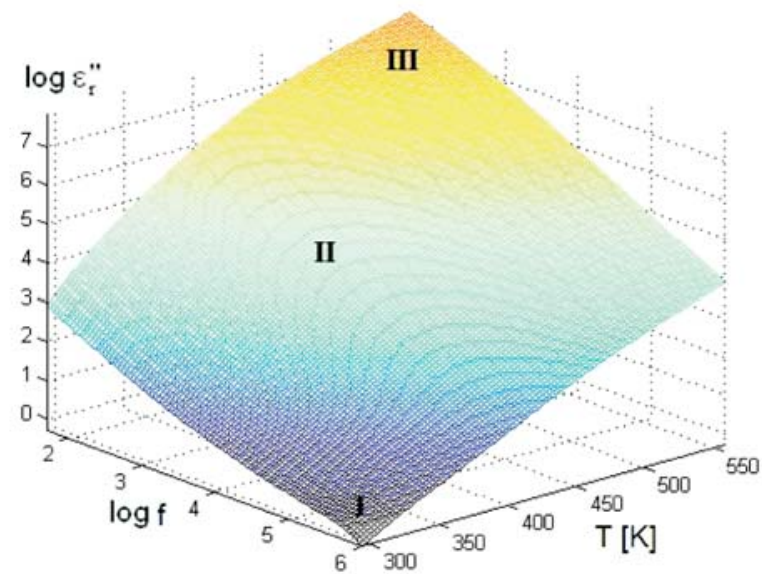

Fig. 2 Temperature and frequency dependence of imaginary part of relative permittivity in $3 D$ form

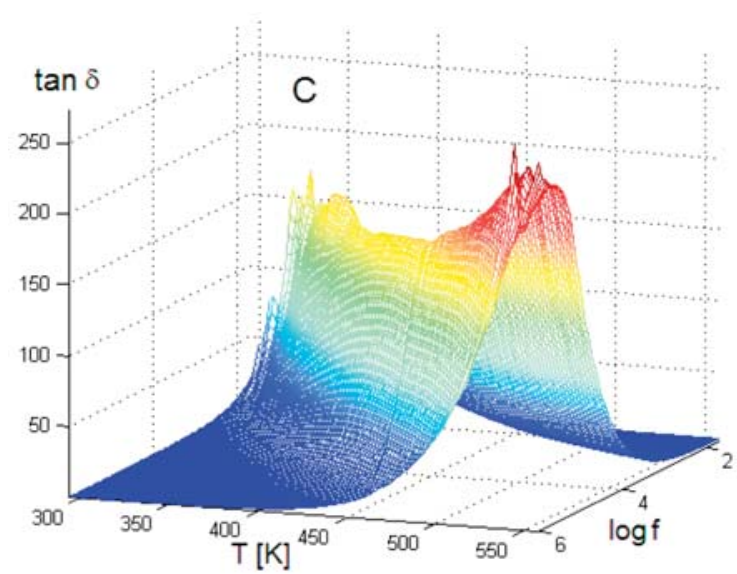

Fig. 3 Temperature and frequency dependence of loss tangent in $3 D$ form

tify three district processes marked by I, II and III parts defined as follows:

(I) Low temperature processes,

(II) Mid temperature processes,

(III) High temperature processes.

(I) This process started over low temperature: $300 \mathrm{~K}$ and it can be appreciated by looking at $\varepsilon_{r}{ }^{\prime}$ at higher frequencies and lower temperatures.

(II) That process extends over mid temperature region (about $350-450 \mathrm{~K}$ ) and over low to moderate frequencies. These processes were observed for $\varepsilon_{r}^{\prime}$ and $\varepsilon_{r}^{\prime \prime}$, respectively.

(III) High temperature process is significant at higher temperatures $(T>500 \mathrm{~K})$. Its amplitude increases rapidly with frequency for both real and imaginary part.

The better resolution is evident from Fig. 3, where the temperature and frequency dependences of loss tangent $\tan \delta(f, T)$ in
$3 \mathrm{D}$ presentation can be seen. It is seen that in the frequency range the only one broad peak was observed with maximum position $\left(\tan \delta\left(T_{\max }\right)\right)$ shifted to higher temperatures with increasing frequency. Some differences can be seen in the temperature range at high and low temperature (two peaks are visible).

It is an established fact that the condition for observing a maximum in the dielectric losses is given by the relation

$$
\omega_{0} \tau_{0}=1
$$

where $\omega_{0}=2 \pi f_{\max }\left(f_{\max }\right.$ is the frequency corresponding to the maximum of $\tan \delta(f))$ and $\tau_{0}$ is the relaxation time. A maximum can be observed when hopping or jumping frequency of ions becomes approximately equal to the frequency of applied field. The shift of maxima in temperature dependencies of the dielectric loss tangent towards to high-frequency side could be due to high values of hopping probability per unit time in the sample.

Typical dependences of real part of the complex permittivity and conductivity at low temperature region $(T=295 \mathrm{~K})$ are shown in Fig. 4.

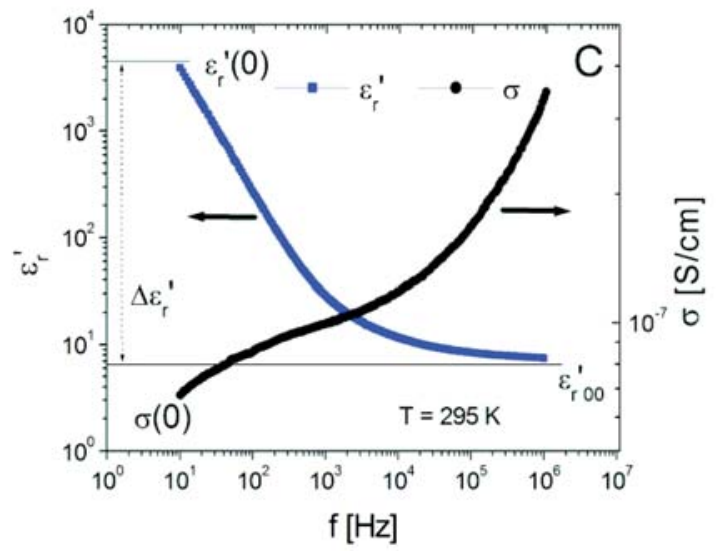

Fig. 4 The measured real part of complex relative permittivity and conductivity at low temperature region $(T=295 \mathrm{~K})$

Here we can see a considerable dependence of both quantities on the frequency $f$ of the applied electric field. Starting at low frequencies, we found a large increase with decreasing frequency of the dielectric constant $\varepsilon_{r}{ }^{\prime}(f)$. It is supposed [8] that in the limit of a dc field, it attains a plateau value. This phenomenon results from the presence of so-called blocking (metallic) electrodes, which do not permit transfer of mobile ions into the external measuring circuit. At low frequencies, it was observed a short plateau in the conductivity $\sigma(0)$ [8]. This so-called dc conductivity represents the long-range diffusion of ions as they hop from site to site through the matrix. We observed a shoulder in the dielectric constant at low frequency range that suggests an incipient polarization occurring in this same frequency range. This polarization is understood to 
be associated with the growth and shrinkage of a dipole that occurs during the hop. This growth and shrinkage is in many respects similar to the rotational relaxation that occurs for a collection of noninteracting permanent dipoles of dipole moment $p$.

On right side of Fig. 4 we can see a dramatic increase in $\sigma(f)$ and a leveling off in $\varepsilon_{r}^{\prime}(f)$. This leveling off of the dielectric constant can occur because, in addition to the mean-squared displacement of mobile ions, matrix contains atoms that have become elastically polarized under the influence of the applied field. The conductivity increases with increasing frequency in a roughly power-law mode. In the high frequency region the data appear to approach a linear dependence of frequency.

It was established [9] that at low frequencies, the dc conductivity implies that the mean-squared displacement is linear and this linear time dependence reflects the random diffusion of the ions which migrate from site to site through the disorded matrix. The time dependent mean-squared displacement was found in the classical random walk model of diffusion and is an identification of uncorrelated motions. At higher frequencies the mean-squared displacement becomes nonlinear and indicates that an ion motion is nonrandom or temporally correlated.

The frequency dependence of the real part $\varepsilon_{r}^{\prime}(f)$ of the complex relative permittivity for sample $\mathrm{C}$ measured at $295 \mathrm{~K}$ approaches a constant value, $\varepsilon_{r \infty}^{\prime}(f)$ at higher frequency, which probably results from rapid polarization processes occurring in the glasses [10]. With decreasing frequency, $\varepsilon_{r}^{\prime}(f)$ increases significantly due to the electrode polarization arising from space charge accumulation at the glass-electrode interface and reaches a low-frequency plateau, $\varepsilon_{r s}^{\prime}$ (static permittivity). This the low-frequency plateau (in $\mathrm{mHz}$ frequency range) usually associated with the polarization effects of the mobile ions. It was proposed $[10,11]$ that the strength of the ionic relaxation determined as $\Delta \varepsilon_{r}^{\prime}=\varepsilon_{r s}^{\prime}-\varepsilon_{r \infty}^{\prime}$ is the magnitude of the permittivity change due to ionic relaxation.

Several other alternative interpretations of the frequency dependences can be found [12]. For example, the electric modulus $M$ is formally defined as the inverse of the complex permittivity

$$
M^{*}(\omega)=1 / \varepsilon_{r}^{*}(\omega)=\varepsilon_{r}^{\prime} /\left(\varepsilon_{r}^{\prime 2}+\varepsilon_{r}^{\prime \prime 2}\right)+j \varepsilon_{r}^{\prime \prime} /\left(\varepsilon_{r}^{\prime 2}+\varepsilon_{r}^{\prime 2}\right) .
$$

Features of this equation are displayed in Fig. 5, where both the real and imaginary parts of the modulus are plotted against frequency for our investigated lithium phosphate glass at room temperature. As we can see the real part of the modulus exhibits a steplike increase with increasing frequency and the imaginary part displays a peaked function.

Complex impedance $\left(Z^{*}=Z^{\prime}-j Z^{\prime \prime}\right)$ plots for sample $\mathrm{C}$ at the temperatures $T=295 \mathrm{~K}$ is illustrated in Fig. 6. The Nyquist plot consists of a depressed semicircle and a spike at the lower frequencies suggesting electrode-electrolyte polarization. This plot was fitted by using an equivalent circuit model of one RC couple in parallel combination (representing the bulk resistance $\mathrm{R}$ and geometric capacitance $\mathrm{C}$ ) in series with one constant phase element



Fig. 5 The real and imaginary parts of the electric modulus for sample $C$ at room temperature

(CPE) (representing polarization at the electrode - electrolyte interface) (in the insert of Fig. 6a)
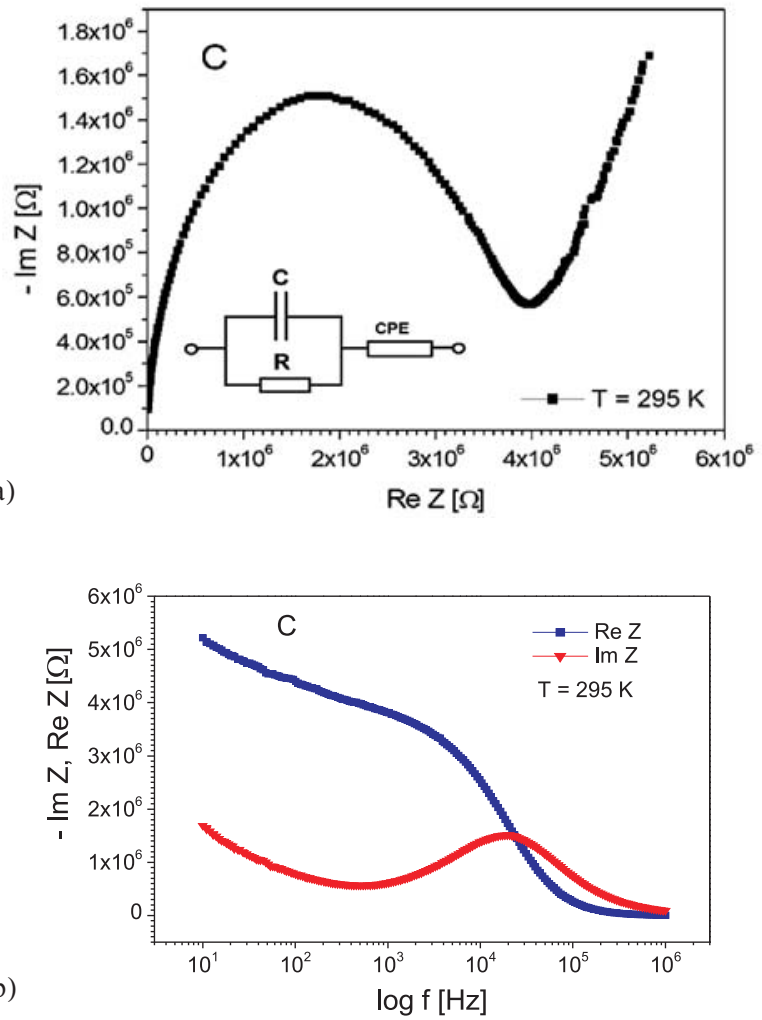

Fig. 6 The impedance plots at temperature $T=295 \mathrm{~K}$ for sample $C$, suitable equivalent circuit is shown inside (a). Plots of real (Re Z) and imaginary (Im Z) part of impedance as function of frequency $(b)$

The $\sigma_{d c}$ at each temperature was calculated using the relation $\sigma_{d c}=d /(R A)$, where $d$ is the thickness of the bulk glass piece and $A$ is the area of cross section of the glass piece. The d.c. conduc- 
tivity at $330 \mathrm{~K}$ is $2.6 \times 10^{-7} \mathrm{~S} / \mathrm{cm}$ which is an increase of one order as compared to $\mathrm{LiPO}_{3}$ glass [13]. The value of d.c. conductivity calculated at the room temperature $(303 \mathrm{~K})$ for sample $\mathrm{C}$ was about $4.3 \times 10^{-8} \mathrm{~S} / \mathrm{cm}$.

A representative Arrhenius plot for sample $\mathrm{C}$ is shown in Fig 7. The temperature dependencies of the d.c. conductivity indicate two transport mechanisms with activation energies $E_{a 1}^{d c}=0.55 \mathrm{eV}$ and $E_{a 2}^{d c}=0.59 \mathrm{eV}$ corresponding to the higher and lower temperatures, respectively. (The activation energy of ionic conductivity determined from another measurements for the LiPON thin film was $0.57 \mathrm{eV}[14,15]$.

The position of the break on the dc conductivity curves (Fig 7) can imply association process [16].

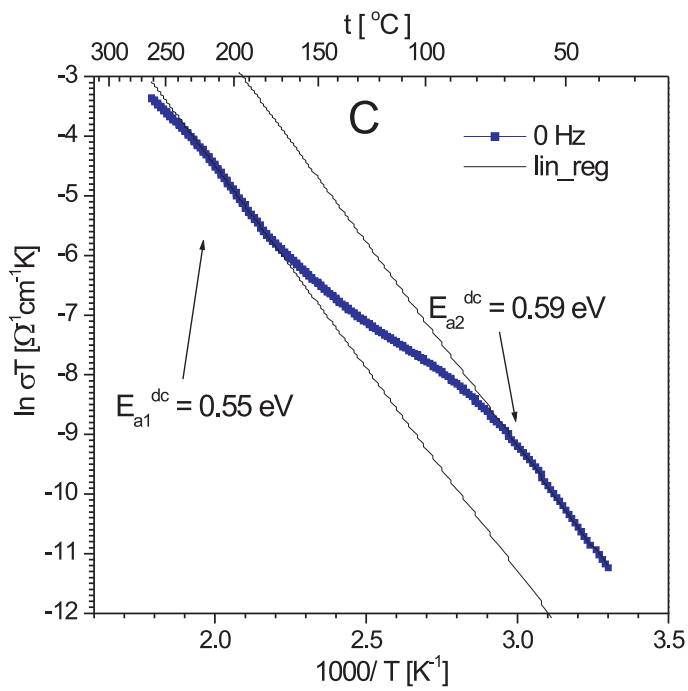

Fig. 7 Temperature dependence of d.c. conductivity

Plotting the frequency of a.c. electric field in logarithmic scale as a function of corresponding inverse temperature of maximum of loss tangent angle (Arrhenius plot), we can then obtain a value of $E_{a 1}^{\operatorname{tg} \delta}=0.52 \mathrm{eV}$ and $E_{a 2}^{\mathrm{tg} \delta}=0.62 \mathrm{eV}$ for activation energy of the dielectric losses.

The set of the frequency dependencies of a.c. conductivity measured at various temperatures (conductivity spectra) is illustrated for the glass sample $\mathrm{C}$ in Fig. 8. The obtained a.c. conductivity measurements correspond to the complete conductivity spectra of glassy samples. However, because of limited frequency range only two regimes (II and III) of the whole conductivity spectra [17] represented by a different slope of individual curves could be recognized, moreover the regime II only at low temperatures. The low frequency part in regime III and the dispersive regime II are due to the hopping motion of the mobile ions and can be obviously explained in terms of a jump relaxation model considering several kinds of sites. The slope of the brakes in the ac conductivity spectra indicates another transport hopping process. The jump from one value of the ac con-

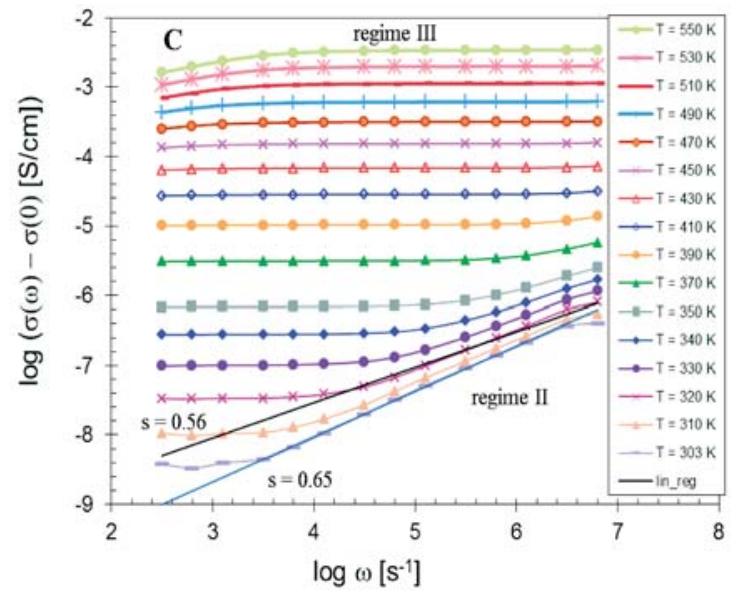

Fig. 8 Representative results obtained from a.c. electrical conductivity measurements for the glass sample $\mathrm{Li}_{1.35} \mathrm{PO}_{3.18}(\mathrm{C})$

ductivity to another was registered at higher temperatures and lower frequencies, characterizing the transition between two kinds of hopping processes. The activation energies calculated from the Arrhenius plots of d.c. conductivity and dielectric measurements for all investigated glasses are summarized in Table 1.

Summarized d.c. conductivities and activation energies

Table 1. calculated from Arrhenius plots $\left(\Delta E_{a}= \pm 0.01 \mathrm{eV}\right)$.

\begin{tabular}{|c|c|c|c|c|c|}
\hline \multirow{2}{*}{$\begin{array}{c}\text { Glass } \\
\text { sample }\end{array}$} & \multicolumn{3}{|c|}{ d.c. } & \multicolumn{2}{|c|}{ a.c. } \\
\cline { 2 - 6 } & $\sigma_{d c}[\mathrm{~S} / \mathrm{cm}]$ & $\begin{array}{c}E_{a 1}^{d c} \\
{[\mathrm{~T}=330 \mathrm{KV})}\end{array}$ & $\begin{array}{c}E_{a 2}^{d c} \\
{[\mathrm{eV}]}\end{array}$ & $\begin{array}{c}E_{a 1}^{\mathrm{tg} \delta} \\
{[\mathrm{eV}]}\end{array}$ & $\begin{array}{c}E_{a 2}^{\mathrm{tg} \delta} \\
{[\mathrm{eV}]}\end{array}$ \\
\hline $\mathrm{B}$ & $1.5 \times 10^{-7}$ & 0.56 & 0.61 & 0.51 & 0.67 \\
\hline $\mathrm{BN}$ & $2.2 \times 10^{-7}$ & 0.54 & 0.60 & 0.52 & 0.64 \\
\hline $\mathrm{C}$ & $2.6 \times 10^{-7}$ & 0.55 & 0.59 & 0.52 & 0.62 \\
\hline
\end{tabular}

Comparing the activation energies obtained from the conductivity and dielectric measurements the relation between d.c. conductivity and activation energy of dominant peak is evident, that means the decrease of activation energy with increasing conductivity.

\section{Discussion}

The both dielectric and conductivity spectra of investigated LiPON glasses suggest two main relaxation and/or transport mechanisms that are also in good agreement with previous investigation by acoustic spectroscopy [18]. The FTIR spectra of the $\mathrm{LiPO}_{3}$ glasses of the system $50 \mathrm{Li}_{2} \mathrm{O} \cdot 50 \mathrm{P}_{2} \mathrm{O}_{5}$ [1] show characteristic peaks corresponding to different vibration modes of the $\mathrm{PO}_{4}$ tetrahedra $\left(v\left(\mathrm{PO}_{4}\right)^{3-}\right.$ sym and $\left.v\left(\mathrm{PO}_{4}\right)^{3-}{ }_{\text {asym }}\right)$ as well as those of the P-O-P bonds $\left(v(\mathrm{P}-\mathrm{O}-\mathrm{P})_{\text {sym }}, v(\mathrm{P}-\mathrm{O}-\mathrm{P})_{\text {asym }}\right.$ and $\left.\delta(\mathrm{P}-\mathrm{O}-\mathrm{P})\right)$ and the $\mathrm{PO}_{2-}$ groups 
$\left(v\left(\mathrm{PO}_{2}\right)^{-}\right.$sym and $\left.v\left(\mathrm{PO}_{2}\right)^{-}{ }_{\text {asym }}\right)$. Using Nuclear Magnetic Resonance it has been found [2] that the oxide glasses marked $\mathrm{B}, \mathrm{C}$ (nitrogen-free) are composed of the $\mathrm{PO}_{4}$ groups of $\mathrm{Q}^{2}$ - type (metaphosphate composition with two bridging oxygen atoms bonded to neighboring phosphorous atoms, cyclic anions of exact $\left.\left(\mathrm{PO}_{3}{ }^{-}\right)_{\mathrm{n}}\right)$ and $\mathrm{Q}^{1}$ structural units (pyrophosphate composition with one bridging oxygen atom bonded to neighboring phosphorous atom, $\mathrm{P}_{2} \mathrm{O}_{7}{ }^{4-}$ groups). Furthermore, the oxynitride glass marked $\mathrm{BN}$ contains also other groups: $\mathrm{PO}_{3} \mathrm{~N}$ and $\mathrm{PO}_{2} \mathrm{~N}_{2}$, which result from nitrogen/ oxygen substitution [19]. These groups increase the cross-linking density giving rise to a notable modification of the glass properties. A higher cross-linking density introduced by the nitrogen atoms should facilitate the lithium transfer between phosphate chains and the higher amount of non-bridging oxygen (NBO) generated by nitridation could increase the number of hopping positions available for $\mathrm{Li}^{+}$ions, creating conduction paths with lower activation energy.

The two main activated processes found from Arrhenius plots of d.c. conductivity and dielectric loss angle tangent maxima might be related to different structural units: Lithium ions bonded to non-bridging oxygen atoms present in $\mathrm{Q}^{2}$ metaphosphate units and $\mathrm{Q}^{1}$ pyrophosphate. From comparison with the IR spectra of LiPON glasses we can draw the assumption that all samples contain dimeric diphosphate oxoanions $\mathrm{P}_{2} \mathrm{O}_{7}{ }^{4-}$ and $\left(\mathrm{PO}_{3}{ }^{-}\right)_{n}$ phosphate chain groups as the dominant structure elements of the glass. The local electric field around the dimeric diphosphate oxoanions $\mathrm{P}_{2} \mathrm{O}_{7}{ }^{4-}$ is stronger than the local electric field around the phosphate chain groups $\left(\mathrm{PO}_{3}^{-}\right)_{n}$ because the triphosphate anions have a smaller negative electric charge on the non-bridging oxygen as diphosphate anion atoms. This causes the electrostatic interactions between the mobile $\mathrm{Li}^{+}$ions and the diphosphate anions to be stronger than those between the $\mathrm{Li}^{+}$ions and the phosphate chain groups. Thus we can suppose that the relaxation processes with bigger activation energies can be connected with diphosphate anions and the processes with smaller energies can be connected with the low condensed triphosphate anions as well as some other polymeric structural units.
The effect of nitrogen on conductivity can be explained by the higher cross-linking density introduced by the nitrogen atoms, which should facilitate the lithium transfer between the phosphate chains. The higher amount of the non-bridging oxygen atoms generated by the nitridation could increase the number of hopping positions available for the $\mathrm{Li}^{+}$ions thus creating conduction paths with lower activation energy and the rise of the electrical conductivity as a consequence of this [2].

However, some differences can be caused by the different relaxation mechanisms connected with the ion hopping transport in a.c. and d.c. electric field [20].

\section{Conclusion}

The experimental investigation of the lithium phosphate and oxynitride phosphate glasses proved that the electrical conductivity and dielectric relaxation spectroscopy can be useful techniques for the study of relaxation processes and transport mechanisms in the $\mathrm{Li}^{+}$ion conductive glasses. Two main kinds of sites responsible for the ionic hopping motion were discovered and described. It was also verified that the nitridation increases the amount of the NBO atoms and the cross-linking density which increases the electrical conductivity of the oxynitride phosphate glasses and decreases the activation energy of conductivity.

\section{Acknowledgment}

The authors would like to thank to Mr. F. Cernobila for technical assistance. This study was supported by the Slovak Grant Agency KEGA through the projects No. 035ZU-4/2012, VEGA No. $1 / 0853 / 13$ and R\&D operational program Centre of excellence of power electronics systems and materials for their components II. No. OPVaV-2009/2.1/02-SORO, ITMS 26220120046 funded by European regional development fund (ERDF).

\section{References}

[1] MOREAU, F., DURAN, A., MUNOZ, F.: Structure and Properties of High $\mathrm{Li}_{2} \mathrm{O}$-containing Aluminophosphate Glasses, J. of the European Ceramic Society 29 (10), pp. 1895-1902, 2009

[2] MUNOZ, F., DURAN, A., PASCUAL, L., MONTAGNE, L., REVEL, B., RODRIGUES, A. C. M.: Increased Electrical Conductivity of LiPON Glasses Produced by Ammonolysis, Solid State Ionics 179 (15-16), pp. 574-579, 2008

[3] YU, X., BATES, J. B., JELLISON, G. E., HART, F. X.: A Stable Thin-Film Lithium Electrolyte: Lithium Phosphorus Oxynitride, J. Electrochem. Soc. 144 (2), pp. 524-532, 1997

[4] GUTTEN, M., KUDELCIK, J.: Methods of Humidity Analysis in Transformer Oil, Communications - Scientific Letters of the University of Zilina 12 (2), pp. 49-52, 2010

[5] VENKATESH, J., SIVASUBRAMANIAN, V., SUBRAMANIAN, V., MURTHYA, V.R.K.: Far-IR Reflectance Study on B-site Disordered $\mathrm{Ba}\left(\mathrm{Zn}_{1 / 3} \mathrm{Ta}_{2 / 3}\right) \mathrm{O}_{3}$ Dielectric Resonator, Materials Research Bulletin 35 (8), pp. 1325-1332, 2000

[6] RICHTER, R., WAGNER, H.: The Dielectric Modulus: Relaxation Versus Retardation, Solid State Ionics 105 (1-4), pp. 167-173, 1998

[7] JONSCHER, A. K.: The 'Universal’ Dielectric Response, Nature 267, pp. 673-679, 1977 
[8] SIDEBOTTOM, D. L., ZHANG, J.: Scaling of the ac Permittivity in Ion-conducting Glasses, Phys. Rev. B 62(9) pp. 5505-5507, 2000

[9] SIDEBOTTOM, D. L.: Colloquium: Understanding Ion Motion in Disordered Solids from Impedance Spectroscopy Scaling, Reviews of Modern Physics 81, pp. 999-1014, 2009

[10] SIDEBOTTOM, D. L., ROLING, B., FUNKE, K.: Ionic Conduction in Solids: Comparing Conductivity and Modulus Representations with Regard to Scaling Properties, Phys. Rev. B 63 024301-024301-7, 2000

[11] SIDEBOTTOM, D. L.: Influence of Cat Ion Constriction on the ac Conductivity Dispersion in Metaphosphate Glasses, Phys. Rev. B 61, pp. 14507-14516, 2000

[12] SIDEBOTTOM, D. L., GREEN, P. F., BROW, R. K.: Anomalous-diffusion Model of Ionic Transport in Oxide Glasses, Phys. Rev. B 51(5), pp. 2770-2776, 1995

[13] PEVZNER, B., HEBARD, A. F., DRESSElHAUS, M. S.: Role of Molecular Oxygen and other Impurities in the Electrical Transport and Dielectric Properties of C60 Films, Phys. Rev. B 55, pp.16439-16449, 1997

[14] FLEUTOT, B., PECQUENARD, B., MARTINEZ, H., LEVASSEUR, A.: Thorough Study of the Local Structure of LiPON thin Films to better Understand the Influence of a Solder-reflow Type Thermal Treatment on their Performances, Solid State Ionics 206, pp. 72-77, 2012

[15] HAMON, Y., DOUARD, A., SABARY, F., MARCEL, C., VINATIER, P., PECQUENARD, B., LEVASSEUR, A.: Influence of Sputtering Conditions on Ionic Conductivity of LiPON thin Films, Solid State Ionics 177 (3-4), pp. 257-261, 2006

[16] KNAUTH, P., TULLER, H. L.: Solid-State Ionics: Root, Status, and Future Prospects, J. of the American Ceramic Society 85 (7) pp.1654-1680, 2002

[17] FUNKE, K., ROLING, B., LANGE, M.: Dynamics of Mobile Ions in Crystals, Glasses and Melts, Solid State Ionics 105 (1-4), pp. 195-208, 1998

[18] HOCKICKO, P., MUNOZ, F., BURY, P., SIDOR, P.: Analysis of Acoustic Attenuation Spectra of LiPON Glasses, Communications - Scientific Letters of the University of Zilina 12 (2), pp. 38-42, 2010

[19] HOCKICKO, P., BURY, P., SIDOR, P., JURECKA, S., JAMNICKY, I.: Mathematical Models for Acoustic Spectra Simulation, Communications - Scientific Letters of the University of Zilina 12 (1) pp. 44-49, 2010.

[20] HOCKICKO, P., BURY, P. MUNOZ, F.: Investigation of Relaxation and Transport Processes in LiPO(N) Glasses, J. of Non-Crystalline Solids 363 (1), pp. 140-146, 2013. 